\title{
Geographic variation in vocalizations of pups and mother-pup behavior of harp seals Pagophilus groenlandicus
}

\author{
I. C. Van Opzeeland ${ }^{1, *}$, P. J. Corkeron ${ }^{2}$, D. Risch $^{3}$, G. Stenson ${ }^{4}$, S. M. Van Parijs ${ }^{2,3}$ \\ ${ }^{1}$ Ocean Acoustics Lab, Alfred Wegener Institute, Am alten Hafen 26, 27568 Bremerhaven, Germany \\ ${ }^{2}$ Bioacoustics Research Program, Cornell Lab of Ornithology, 159 Sapsucker Woods Road, Ithaca, New York 14850, USA \\ ${ }^{3}$ Northeast Fisheries Science Center, NOAA, 166 Water Street, Woods Hole, Massachusetts 02543, USA \\ ${ }^{4}$ Dept. of Fisheries and Oceans, Northwest Atlantic Fisheries Center, PO Box 5667, St. John's, Newfoundland A1C 5X1, Canada
}

\begin{abstract}
All harp seal populations form breeding aggregations on the Arctic pack ice. However, pack ice conditions vary spatially and temporally among these aggregations with variation in environmental and oceanographic conditions, which may affect the behavioral interactions between mothers and their newborn pups. We investigated the variation in mother-pup behavior between harp seal breeding aggregations in the NE (Greenland Sea) and NW Atlantic coastal shelf region (Front). Acoustic cues provided by the pups are thought to be important in facilitating reunions with their mothers. Consequently, we measured variation in vocal parameters among seals to investigate geographic differences in pup vocalizations. Classification trees showed a distinctive split between Front and Greenland Sea pup vocalizations. There were no clear differences between male and female pups at the Front, where $42 \%$ of male and $38 \%$ of female pup calls could be attributed to a given individual. This contrasts with the Greenland Sea, where $55 \%$ of vocalizations of female pups were attributed to individuals compared with only $8 \%$ for males. Analyses of behavioral observations of mother-pup pairs made in the afternoon and evening showed that pups in the Greenland Sea suckled more and were more alert than pups in the Front. Further, mother-pup attendance patterns differed between sites. Mothers at the Front attended their pups $85.1 \%$ of the time, whereas mothers in the Greenland Sea attended their pups $52.2 \%$ of the time. These substantial differences between sites might be related to evolutionary changes in behavior resulting from commercial hunting or variable environmental conditions.
\end{abstract}

KEY WORDS: Harp seal · Pagophilus groenlandicus - Pup vocalizations · Mother-pup behavior · Geographic variation · Climate change Resale or republication not permitted without written consent of the publisher

\section{INTRODUCTION}

Geographic variation in behavioral traits offers opportunities to make inferences about selective pressures that may influence behavior and the degree of differentiation among populations. Geographic variation in behavioral traits is common to a variety of taxa and has been described in various behavioral contexts ranging from dietary preferences in garter snakes Thamnophis elegans to migratory routes in blackcaps Sylvia atricapilla and antipredator behavior in ground squirrels Spermophilus beecheyi (see Foster 1999 for a review). Research efforts into geographic variation in behavioral traits have, however, largely focused on variation in behavior of adults within populations. Less is known about differences in the behavior of young and juveniles.

In pinnipeds, geographic variation in behavioral traits such as mother-offspring interactions and male display behavior has been documented in a number of species (Terhune 1994, McCulloch \& Boness 2000, Van Parijs et al. 2000). Several studies have also reported geographic variation in the vocalizations of pinniped species. In harbour seals Phoca vitulina, variation in 
vocal behavior occurs between genetically isolated populations. However, site-specific vocalizations are also present between genetically mixed groups, suggesting site-specific selection for changes in certain vocal parameters that may be driven by local ecology or climate or both (Van Parijs et al. 2000, 2003, 2004).

In many pinniped species vocal behavior is important in female recognition of offspring during the lactation period (Insley et al. 2003). Insley (1992) suggested that although many pinniped species exhibit individually stereotyped vocalizations, the degree to which selection has favoured development of a vocal recognition system may vary with the reproductive environment of different species. Female grey seals in 2 reproductively isolated populations were found to respond differently to playbacks of vocalizations of their own pups (McCulloch \& Boness 2000). Females on Sable Island, Nova Scotia, were found to discriminate between calls of their own and non-filial pups, while on the Isle of May, females failed to recognize the calls of their own pup (McCulloch et al. 1999). The fact that allo-suckling (i.e. non-offspring nursing) was more frequently observed in pups on the Isle of May than on Sable Island may also indicate differences in pup behavior between the 2 colonies.

In ice-breeding seals, females form dispersed aggregations on the ice during the breeding season (Lydersen \& Kovacs 1999, Van Parijs et al. 2001). In most species, females may have to forage to sustain late lactation, leaving their pup alone on the ice (e.g. Testa et al. 1989, Lydersen \& Kovacs 1999). The relocation process is often complicated by hourly or daily movements of the ice, causing pups to drift away from where they were when their mothers left. However, the stability of the breeding substrate used can differ substantially between different species and sites, ranging from large stable ice floes with breathing holes through which females return to their young, to small mobile ice floes or pack ice, the location and size of which is often heavily influenced by currents and weather conditions (Terhune et al. 1979, Lydersen \& Kovacs 1993). To date, little is known about which, and how, factors such as the role of ice conditions influence mother-pup reunions in most ice-breeding seals.

Harp seals Pagophilus groenlandicus are ice-breeding seals and the most abundant pinnipeds in the North Atlantic. There are 3 populations: (1) the White Sea/Barents Sea population, (2) the NW Atlantic population, subdivided into a Gulf of St Lawrence ('Gulf') component and a coastal shelf component off NE Newfoundland and/or southern Labrador ('Front'), and (3) the Greenland Sea (NE Atlantic) population, which breeds on the pack ice between eastern Greenland and Jan Mayen (Sergeant 1991). Several studies have found genetic separation between NE and NW
Atlantic harp seals (Meisfjord \& Sundt 1996, Perry et al. 2000).

All harp seal populations form large breeding aggregations on the ice. The whelping period varies somewhat between populations, but is strongly synchronous within populations, with the majority of pups in an aggregation born within a very short (3 to 4 d) period. Nursing lasts around 10 to $12 \mathrm{~d}$ (Sergeant 1991). During this period females spend a few hours each day in the water, leaving their pups alone on the ice. Alongside visual, olfactory and spatial cues, acoustic cues provided by the pup are likely to play an important role in the relocation process. Ice conditions, such as the rate of ice drift, the type of ice that is used for breeding and ice concentration, vary annually and between the different breeding locations of populations (Wilkinson \& Wadhams 2005, Friedlaender et al. 2007). The breeding substrate in the Gulf of St. Lawrence consists of large stable ice planes with breathing holes. It is thought that this substrate enables the female to predominantly use spatial cues during the relocation of her pup (Kovacs 1995). In contrast to the situation in the Gulf, the ice pack encountered off Newfoundland (Front) is usually made up of small mobile seasonal (first-year) ice floes (G. Stenson pers. obs.). In the NE Atlantic, the ice pack encountered in the Greenland Sea mainly consists of perennial (multi-year) ice floes. Each of these ice types has distinctive physical (e.g. thickness, albedo and roughness) and biological characteristics (Snack-Schiel 2003).

Our aims in this study were to investigate (1) whether vocal characteristics of harp seal pups vary geographically, and (2) whether behaviors of mothers and their pups differ between the breeding areas in the Front and the Greenland Sea.

\section{MATERIALS AND METHODS}

Data collection. We recorded vocalizations and behavior of suckling harp seal pups and female attendance patterns during 2 study periods at 4 breeding sites, 2 in the Greenland Sea and 2 off southern Labrador-northeast coast of Newfoundland (Front). Because of the difference in timing of whelping in the 2 areas, the study in the Greenland Sea was carried out from 18 to 30 March 2002 and the study in the Front was conducted from 10 to 22 March 2004 to ensure that pups of similar age were present.

Data collection for the Greenland Sea and the Front were carried out in conjunction with harp seal abundance surveys run by the Institute of Marine Research in Norway and the Department of Fisheries and Oceans in Canada (see Haug et al. 2006 and Stenson et al. 2005 for descriptions of the surveys). Once breeding aggre- 
gations were located, data collection on mothers and pups was carried out from ice-strengthened vessels either directly or as a base for helicopters.

The breeding aggregations in the Greenland Sea were situated in the pack ice areas northeast of Jan Mayen, centred around $72^{\circ} 14^{\prime} \mathrm{N}, 12^{\circ} 43^{\prime} \mathrm{W}$ (Patch GS-A) and $72^{\circ} 10^{\prime} \mathrm{N}, 13^{\circ} 10^{\prime} \mathrm{W}$ (Patch GS-B, Fig. 1). These correspond to patches A and B in Haug et al. (2006). At the Front, the patches were situated off the coast of southern Labrador around $50^{\circ} 46^{\prime} \mathrm{N}, 55^{\circ} 19^{\prime} \mathrm{W}$ (F-A) and $51^{\circ} 28^{\prime} \mathrm{N}, 55^{\circ} 07^{\prime} \mathrm{W}$ (F-B, Fig. 1). These were referred to as the Cartwright and Belle Isle concentrations, respectively, by Stenson et al. (2005). The estimate of the number of pups in patch GS-A was 4700 and in patch GS-B was 82600 (Haug et al. 2006); the estimate in patch F-A was 368705 and in patch F-B was 272074 pups (Stenson et al. 2005).

Pup vocalizations. We chose groups of pups to record based on safe access by helicopter or vessel to ice floes where several pups were within walking distance. The helicopter landed within a few meters of the nearest mother-pup pair. Landings and lift-offs were as short as possible in order to minimize disturbance. Helicopter landings frequently caused the nearest pups to start vocalizing, while mothers sometimes left the ice. However, mothers and pups were usually reunited within minutes of the helicopter taking off. In the case that females and their pups were noticeably disturbed by the helicopter landing and take off, we concentrated on recording pups that showed no disturbance or waited until behavior of disturbed animals had returned to normal before recording. In the Greenland Sea herd we caught all pups that we recorded and tagged them with a Dalton roto-tag in the webbing of the right rear flipper. This tag has been developed for long-term identification of domestic sheep and goats. Studies on a variety of species have shown that piercing caused by the insertion of the rototag heals quickly, with no apparent detrimental effect on the behavior of the individuals or apparent change in behavior of other individuals towards tagged individuals (Testa \& Rothery 1992). In harp seals, the wound caused by insertion of the roto-tag caused little to no bleeding and had healed cleanly in all pups that were revisited on subsequent days. During the tagging and recording procedures, mothers left their pups and watched from a distance either from another flow or from the water. For all pups tagged during this study, reunion between mother and pup occurred within minutes after the observers left the pup. At the Front, study areas were marked with dye and visited only once to make acoustic recordings of individual pups. Within each study area recordings were made of 5 to 10 ind. and the recorder was therefore able to visually identify which pups had been recorded.

We determined the sex and approximate age (based on pelage-specific developmental stages; see Table 2 in Kovacs 1987) of each pup in both areas.

We used an MD 421-II microphone (Sennheiser; sensitivity $170 \mathrm{~dB}$, frequency bandwidth $36 \mathrm{~Hz}$ to $17 \mathrm{kHz} \pm$ $3 \mathrm{~dB}$ ) connected to a TCD-D8 digital audiotape recorder (Sony; frequency response $5 \mathrm{~Hz}$ to $22 \mathrm{kHz}$ ) to record pup vocalizations. The microphone was held 0.1 to $0.3 \mathrm{~m}$ from the vocalizing pup. Recordings were made for about 5 min for each pup and included 51 calls, on average, for each pup in both areas. The responses to our presence varied among pups, but overall they showed little or no reaction when we approached closely to record. Recording techniques were similar at each site to minimize variation in pup response to the recordings. The recordings were re-sampled (sampling frequency $22 \mathrm{kHz}$, dynamic range $170 \mathrm{~dB}$; the highest frequencies within pup vocalizations were below $11 \mathrm{kHz}$ ) and spectrographic analyses (fast Fourier transformations - time resolution: $10 \mathrm{~ms}$; frequency resolution: $102 \mathrm{~Hz}$; FFT size: 512) were conducted using the sound analysis program Raven 1.2 (Bioacoustics Research Program, Cornell Lab of Ornithology).

Calls for which one or more of the vari-
Fig. 1. Pagophilus groenlandicus. Study sites where vocalizations and behavioral observations of harp seal mother-pup pairs were made: the Front (1) and the Atlantic Greenland Sea (2). The insets show the whelping patches for the Front (F-A and F-B) and the Greenland Sea (GS-A and GS-B) where the data were collected 
ables could not be measured were omitted from the analyses.

Using overall call shape, each signal was assigned a signal type (i.e. tonal call, pulsed call or a combination of the 2; see Miller \& Murray 1995, Fig. 2 in Van Opzeeland \& Van Parijs 2004). Tonal calls typically had a harmonic structure. Pulsed calls were characterized by a pulsed signal, lacking harmonic structure. As several acoustic variables could not be measured from the pulsed and combination vocalizations, these signal types were not included in subsequent analyses. Therefore we only used tonal calls in these analyses. Our recordings were consistent with the observations of Kovacs (1987), that tonal vocalizations were primarily associated with nursing, whereas pulsed signals were clearly related to situations in which pups felt threatened by the presence of the recorder or other seals nearby and were not considered to be pure mother attraction calls. Individuals with fewer than 15 recorded tonal vocalizations were excluded from analyses.

For the Front, we measured 10 vocal parameters for each tonal call (Fig. 2): (1) call duration (DURN); (2 to 4) three harmonics of greatest amplitude (PF1 to PF3);

(5) the number of harmonics (HARM);

(6) the maximum frequency of the lower harmonic (SH1); (7) the maximum frequency of the second harmonic (EH1); (8) the duration of the ascending part of the call (DURASC); (9) the duration of the plateau part (DURPLAT); and (10) the duration of the descending part of the call (DURDESC). In an earlier study on harp seal pup vocal behavior (Van Opzeeland \& Van Parijs 2004), these parameters were measured for a subset of the data from the Greenland Sea (10 randomly selected individuals: $\mathrm{N}=5$ males and 5 females) to explore which parameters were important in individual variation. Seven vocal parameters (1 to 7) were highlighted as important. Therefore for the Greenland Sea data set, further analysis of the whole data set of tonal calls was carried out on only 7 of the vocal parameters (see Van Opzeeland \& Van Parijs 2004 for more details).

Because of wind noise during recordings made at the Front we could not make good counts for HARM values in many cases. Consequently, we removed this parameter (i.e. HARM) from the Front data set. We included 9 vocal parameters in further analyses of the Front data.
We assessed variation in vocal parameters among pups using classification trees (CART). The data did not follow a normal distribution and were therefore log-transformed. Analyses were carried out in R ( R Development Core Team 2007, version 2.5.1, www. R-project.org), running under MS Windows; and the RPART library (v.3.1-36, Therneau \& Atkinson 2004) for CARTs. As opposed to other multivariate techniques such as discriminant analyses and principal component analyses, CART analyses provide a useful technique for exploring multivariate nonparametric data. Furthermore, CART analyses produce a result that is readily visually accessible (see Risch et al. 2007 for a detailed explanation of this analysis). We used 9 vocal parameters for analyses of Front data except when comparing them with data from the Greenland Sea, when we used only the 7 vocal parameters obtained from both areas in the comparative analyses.

Mother-pup behavior. Visual observations of mother-pup behavior were made from the ship drifting within the whelping aggregations using $7 \times 50$ binoculars (Zeiss) over $10 \mathrm{~d}$ in the Front and $13 \mathrm{~d}$ in the Greenland Sea. Behavioral observations in both areas
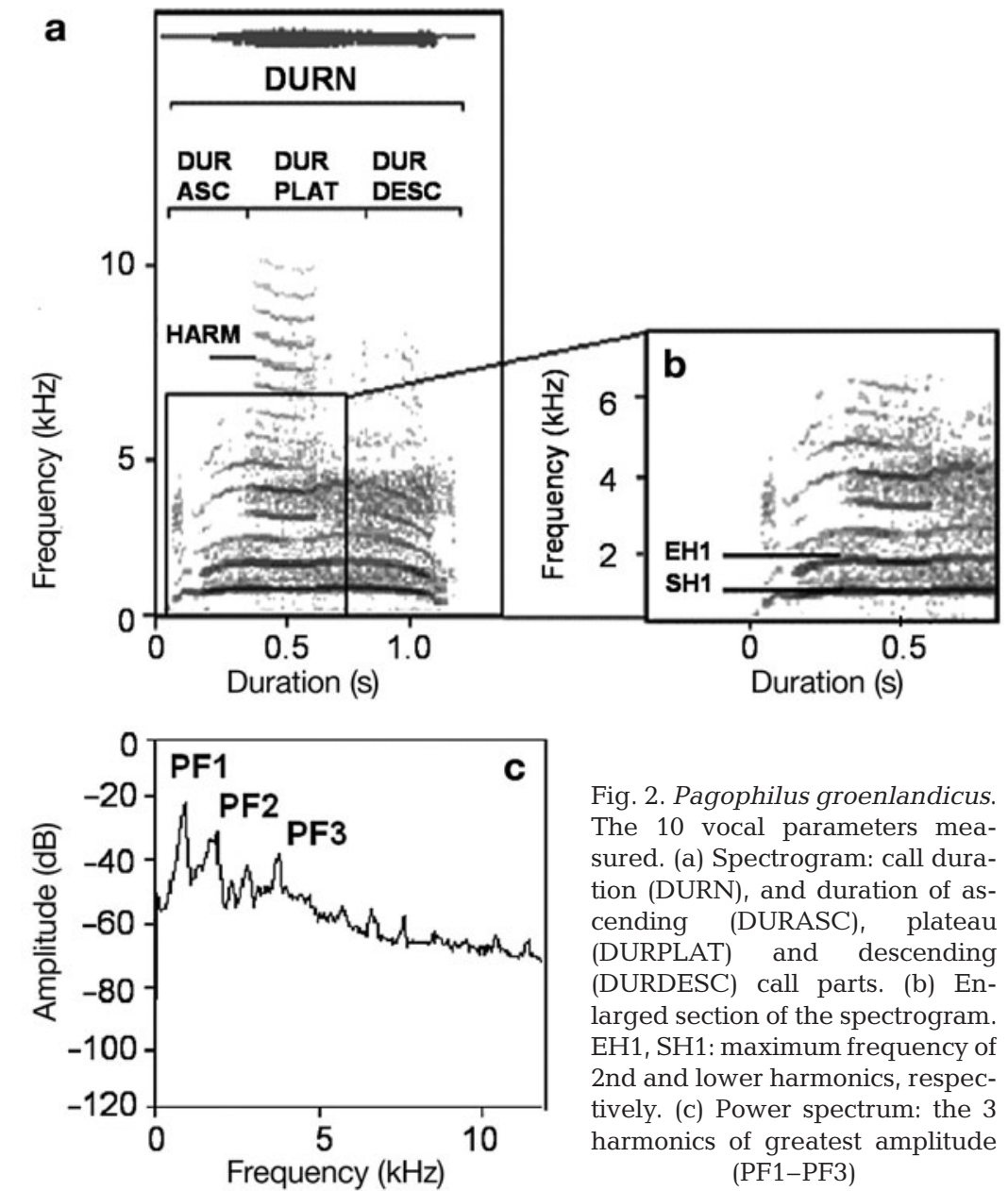

Fig. 2. Pagophilus groenlandicus. The 10 vocal parameters measured. (a) Spectrogram: call duration (DURN), and duration of ascending (DURASC), plateau (DURPLAT) and descending (DURDESC) call parts. (b) Enlarged section of the spectrogram. EH1, SH1: maximum frequency of 2nd and lower harmonics, respectively. (c) Power spectrum: the 3 harmonics of greatest amplitude (PF1-PF3) 
were made when no persons were on the ice. We recorded behaviors of pups and female attendance patterns in 30 min blocks using scan sampling of motherpup pairs at $30 \mathrm{~s}$ intervals (according to the methods used by Kovacs 1987 in the Gulf of St. Lawrence). Because of the relatively large distance between the observer and the mother-pup pairs we were not able to determine the sex of the pups observed from the ship.

We defined female attendance as the time spent by the female on the ice in the same area as her pup, regardless of her behavioral state (Kovacs 1987). There is a diurnal pattern to these attendance patterns with attendance increasing in the late afternoon and evening (Kovacs 1987). In the Greenland Sea behavior was recorded between 16:00 and 19:30 h. A few observations were also made before $16: 00 \mathrm{~h}$, but there were too few to include in the analyses. At the Front we made observations between 07:00 and 17:00 h. Because of latitudinal differences between the 2 study sites (Fig 1), time prior to local sunset differed between the 2 sites. Therefore, analyzing the data between 16:00 and 17:00 h, when data collection overlapped between the 2 sites, would not completely preclude some time-of-day effect. Therefore, we restricted the analyses to data collected after 16:00 h.

We observed 3 to 6 mother-pup pairs simultaneously; the developmental stage of each pup and behavioral state was determined for each seal under observation on each scan. Behavioral states were defined according to Kovacs 1987 (Table 1). Although Kovacs (1987) identified 18 behaviors, we did not observe all of the behaviors in either the Greenland Sea or the Front. Four of the behaviors (sexual, low threat, high threat, and fighting) were not observed in either study area. Four others (presentation, check pup, foreign social, and pup agonistic) were seen only in the Greenland Sea. Behavioral states for which there were $<2$ observations were eliminated from the set. Eight units of behavior (idle, comfort movements, nursing, nosing, locomotion, swimming, exploration, and alert) were observed often enough for analyses.

In line with Kovacs (1987), we selected pups opportunistically during scanning sessions, without reference to maternal presence or absence. Each observation session lasted 30 min, after which a new set of mother-pup pairs was selected and a new session started. Because the research vessel was drifting through the ice pack, 30 min was a conservative limit during which all pairs clearly remained within visual range. No pairs were sampled for more than 1 session. A linear model tested for the effects of site, pup stage and site-stage inter-

Table 1. Pagophilus groenlandicus. Behavioral criteria used to define behavioral states recorded during scanning sessions (from Kovacs 1987, their Table 1)

\begin{tabular}{|c|c|}
\hline Behavioral state & Criteria \\
\hline Idle & $\begin{array}{l}\text { Resting motionless in a prone position on the ice } \\
\text { (eyes open or closed) }\end{array}$ \\
\hline Comfort movements & $\begin{array}{l}\text { In a prone position performing low intensity activi- } \\
\text { ties, including weight shifting, stretching, etc., and } \\
\text { in the case of pups, 'wriggling' without changing } \\
\text { location, and shivering for young pups }\end{array}$ \\
\hline Nursing & $\begin{array}{l}\text { Female lying quiescent on her side, nipples } \\
\text { exposed, pup in oral contact with the nipples (time } \\
\text { spent moving between nipples was included as } \\
\text { part of the nursing sequence) }\end{array}$ \\
\hline Presentation & $\begin{array}{l}\text { Female postures such that the nipples are accessi- } \\
\text { ble to the pup, often accompanied by gentle } \\
\text { motions of the female's foreflipper that was furthest } \\
\text { from the surface }\end{array}$ \\
\hline Nosing & $\begin{array}{l}\text { Non-nursing physical contact between a mother } \\
\text { and her pup, consisting of naso-nasal or naso-body } \\
\text { contact }\end{array}$ \\
\hline Check pup & $\begin{array}{l}\text { Female makes visual contact with her pup, turning } \\
\text { her head if necessary }\end{array}$ \\
\hline Foreign social & $\begin{array}{l}\text { Non-agonistic, non-sexual physical contact outside } \\
\text { the mother-pup pair }\end{array}$ \\
\hline Sexual & Attempted mounting or copulatory behavior \\
\hline Low threat & $\begin{array}{l}\text { Female on ventum with head elevated from the ice, } \\
\text { neck extended, mouth open and vibrissae erect, } \\
\text { often accompanied by low growling vocalizations }\end{array}$ \\
\hline High threat & $\begin{array}{l}\text { Female on ventum with entire upper body elevated } \\
\text { from the ice, nose held vertically, vibrissae held } \\
\text { erect, often accompanied by a 'warbling' vocaliza- } \\
\text { tion and rapid clawing of the ice with a foreflipper }\end{array}$ \\
\hline Fighting & $\begin{array}{l}\text { Female makes physical contact with another adult } \\
\text { animal, biting, clawing or pushing }\end{array}$ \\
\hline Attack pup & Female biting or clawing a pup \\
\hline Pup agonistic & $\begin{array}{l}\text { Pup growling accompanied by a variety of 'alert' } \\
\text { body positions or lunging directed toward another } \\
\text { animal }\end{array}$ \\
\hline Locomotion & Changing topographical location on the ice \\
\hline Swimming & $\begin{array}{l}\text { Time spent by a pup in the water, whether or not it } \\
\text { appeared to change location }\end{array}$ \\
\hline Exploration & $\begin{array}{l}\text { Pup investigating or manipulating an object or } \\
\text { another pup, using its vibrissae, nose, mouth or } \\
\text { foreflippers }\end{array}$ \\
\hline Play & $\begin{array}{l}\text { Repeated, exaggerated, jerky or 'wriggling' body } \\
\text { movements, often accompanied by loud growling } \\
\text { directed toward ice or skyward }\end{array}$ \\
\hline Alert & $\begin{array}{l}\text { Head and upper body elevated from the ice sur- } \\
\text { face, eyes open, animal frequently on ventrum with } \\
\text { foreflippers gripping the ice }\end{array}$ \\
\hline
\end{tabular}


action. We tested whether the suite of behaviors displayed by pups varied by site, pup stage class, and the interaction between these. We did this using the matrix of behavior with pups as rows, behaviors as columns. Behavioral matrices were compared using the function Adonis in vegan R-package (v. 1.8-8, Oksanen et al. 2007), running what is functionally a nonparametric MANOVA (Anderson 2001). This technique partitions sums of squares of a multivariate data set, thus allowing hypothesis testing. It differs from MANOVA (but is similar to AMOVA, Excoffier et al. 1992) in using the outer product matrix of the response matrix (MANOVA uses the inner product matrix). By doing so, semi-metric or metric distance matrices can be tested (Anderson 2001, Oksanen et al. 2007). Significance testing is achieved through permutations of raw data (Oksanen et al. 2007).

The matrix was row-standardized so that the analysis was of the proportions of different units of behavior exhibited by individual seal pups. As the data were proportions of unbalanced count data, we used Horn's modification of Morisita's index (Oksanen et al. 2007) to generate a distance matrix from the standardized behavioral matrix. Testing of the linear model was based on 1000 permutations.

In addition, we tested whether there was a site effect on female attendance. As the data were binomial (females present or absent) and over-dispersed (mean 39.9, variance 512.98), we ran a quasi-binomial generalized linear model (Venables \& Ripley 2002) with logistic link function. This analysis was carried out using R (v.2.5.1) and the MASS library (v.7.2-36, Venables \& Ripley 2002). Where significance was tested for, we accepted an $\alpha$ value of 0.05 as significant.

\section{RESULTS}

\section{Vocal behavior of pups}

After quality selection of the Front data set, 984 calls from 25 pups (12 males, 13 females) were suitable for further analyses (Tables $2 \& 3$ ).

An initial 33-node classification tree was pruned with cross-validation. The 1-SE rule (i.e. the smallest tree for which the cross-validated relative error rate is within 1 SE of the minimum; De'ath \& Fabricius 2000) suggested that the appropriate descriptive tree was one with 11 nodes (Fig. 3 ). The analysis correctly classified $32 \%$ (315 out of 984) of calls according to individual for the Front data set (Fig. 3). The first major split was based on PF1. The next 2 splits occurred at SH1 and at other values of PF1, followed by splits based on DURN and SH1. Of the 13 female pups, $38 \%$ were classified correctly according to individual. For
Table 2. Pagophilus groenlandicus. Descriptive statistics of the 9 mother-pup call parameters measured for 12 male (M) and 13 female (F) harp seal pups recorded in the Front. DURN: duration (ms); PF1-PF3: 1st, 2nd and 3rd peak frequency $(\mathrm{kHz})$; SH1, EH1: maximum frequency of the lower and 2nd harmonic, respectively $(\mathrm{Hz})$; duration of ascending (DURASC), plateau (DURPLAT) and descending (DURDESC) call parts, respectively (ms)

\begin{tabular}{|lcccc|}
\hline \multirow{2}{*}{ Vocal parameters } & Sex & N & Mean \pm SD & CV (\%) \\
\hline DURN & F & 512 & $833.3 \pm 282.9$ & 34 \\
& $\mathrm{M}$ & 472 & $907.1 \pm 333.3$ & 37 \\
PF1 & $\mathrm{F}$ & 512 & $1.4 \pm 0.6$ & 40 \\
& $\mathrm{M}$ & 472 & $1.2 \pm 0.4$ & 36 \\
PF2 & $\mathrm{F}$ & 512 & $1.8 \pm 0.8$ & 43 \\
& $\mathrm{M}$ & 472 & $1.7 \pm 0.6$ & 38 \\
PF3 & $\mathrm{F}$ & 512 & $2.5 \pm 1.2$ & 47 \\
& $\mathrm{M}$ & 472 & $2.5 \pm 1.0$ & 39 \\
SH1 & $\mathrm{F}$ & 512 & $859.2 \pm 181.3$ & 21 \\
& $\mathrm{M}$ & 472 & $876.2 \pm 154.5$ & 18 \\
EH1 & $\mathrm{F}$ & 512 & $1680.1 \pm 333.5$ & 20 \\
& $\mathrm{M}$ & 472 & $1707.3 \pm 290.6$ & 17 \\
DURASC & $\mathrm{F}$ & 382 & $0.2 \pm 0.1$ & 47 \\
DURPLAT & $\mathrm{M}$ & 347 & $0.2 \pm 0.1$ & 56 \\
& $\mathrm{~F}$ & 401 & $0.7 \pm 0.3$ & 40 \\
DURDESC & $\mathrm{M}$ & 372 & $0.7 \pm 0.3$ & 43 \\
& $\mathrm{~F}$ & 336 & $0.1 \pm 0.1$ & 64 \\
& $\mathrm{M}$ & 294 & $0.1 \pm 0.1$ & 58 \\
\hline
\end{tabular}

Table 3. Pagophilus groenlandicus. Descriptive statistics of the vocalizations of 49 male (M) and 42 female (F) harp seal pups recorded in the Greenland Sea (from Van Opzeeland \& Van Parijs 2004). HARM: number of harmonics; all other abbreviations as in Table 2

\begin{tabular}{|lcccc|}
\hline \multirow{2}{*}{ Vocal parameters } & Sex & N & Mean \pm SD & CV (\%) \\
\hline DURN & F & 1173 & $871.2 \pm 276.2$ & 32 \\
& $\mathrm{M}$ & 1188 & $855.8 \pm 595.7$ & 70 \\
PF1 & F & 1173 & $1.2 \pm 0.4$ & 32 \\
& $\mathrm{M}$ & 1188 & $1.1 \pm 0.4$ & 32 \\
PF2 & $\mathrm{F}$ & 1173 & $2.1 \pm 0.6$ & 31 \\
& $\mathrm{M}$ & 1188 & $1.9 \pm 0.8$ & 40 \\
PF3 & $\mathrm{F}$ & 1173 & $3.1 \pm 0.7$ & 23 \\
& $\mathrm{M}$ & 1188 & $2.8 \pm 1.1$ & 39 \\
HARM & $\mathrm{F}$ & 1173 & $10.9 \pm 6.1$ & 56 \\
& $\mathrm{M}$ & 1188 & $11.8 \pm 7.0$ & 60 \\
SH1 & $\mathrm{F}$ & 1173 & $1042.7 \pm 282.1$ & 27 \\
& $\mathrm{M}$ & 1188 & $1016.4 \pm 274.6$ & 27 \\
EH1 & $\mathrm{F}$ & 1173 & $1675.5 \pm 451.9$ & 27 \\
& $\mathrm{M}$ & 1188 & $1586.5 \pm 454.5$ & 29 \\
\hline
\end{tabular}

the 12 males, $42 \%$ were correctly classified. For the Greenland Sea data set, $43 \%$ of calls were correctly classified according to individual. The first major split was based on PF3 and separated male and female pups. Of the 42 female pups, $55 \%$ were classified correctly according to individual, whereas $8 \%$ of 49 male pups were correctly classified. 


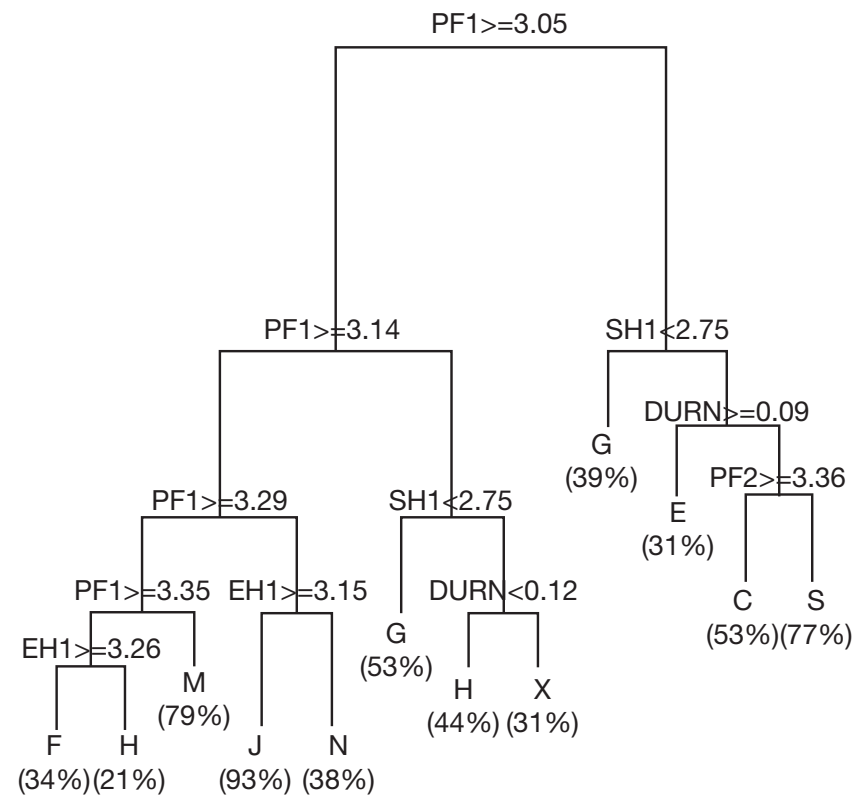

Fig. 3. Pagophilus groenlandicus. An 11-node classification tree showing how vocalizations from 25 harp seal pups recorded in the Canadian Front split, based on log-transformed data of 12 measured vocal parameters: call duration (DURN), 3 harmonics of greatest amplitude (PF1-PF3), the maximum frequency of the lower and 2nd harmonic (SH1, EH1, respectively). Letters at the bottom of the tree represent individual pups. Percentages indicate the percentage of calls that were classified correctly according to individual for the individual pups. Twelve of the 25 ind. were extracted by this analysis, explaining $52 \%$ of the total variation. The vertical depth of each split explains the proportion of total variation explained by that split. Splits early in the tree (i.e. near the top of the page) account for more variability in the data than those lower down in the tree

In order to compare pup vocal behavior between the Greenland Sea and the Front, a CART was run, using site as response variable. With no misclassifications, $100 \%$ of the variation in pup calls was explained in the first split, demonstrating a clear difference between pup vocal characteristics and site. DURN was found to be the vocal parameter driving the split between pup calls recorded in the Greenland Sea and pup calls recorded in the Front. Pups from the Greenland Sea had calls that were longer in duration (greater than 1.2 s) compared with Front pups. Table 4 summarizes the results of the CARTs for individual and sex differences within vocalizations recorded in the Greenland Sea and the Front.

\section{Mother-pup behavior}

A total of $46 \mathrm{~h}$ of scan samples were collected and a total of 91 mother-pup pairs were observed in the Greenland Sea ( $\mathrm{N}=4941$ observations). In the Front, $85 \mathrm{~h}$ of scan samples were collected and a total of 180 pairs ( $\mathrm{N}=10657$ observations) were observed. After discarding data collected before 16:00 $\mathrm{h}$, there were data on 136 pups (58 Front, 78 Greenland Sea). Kovacs's (1987) units of behavior were used (Table 1). As data were collected on only 2 Stage 4 pups at either site, these were concatenated with Stage 3 pups into a Stage 3+ category. There was a significant Site effect, but no effect of Stage or Site $\times$ Stage interaction (Table 5).

Review of the raw data (Fig. 4) suggested that pups in the Front spent more time idle, whereas Greenland Sea pups suckled more and were more alert than pups at the Front. We tested whether there was a site effect on female attendance using a quasi-binomial generalized linear model (GLM) with log link (Venables \& Ripley 2002). This demonstrated a significant effect of site on female attendance. Females in the Greenland Sea were less likely to be present on the ice with their pups than those at the Front (Table 6). In late afternoon and evening, females in the Greenland Sea were with their pups around half the time (average time in attendance $=52.2 \pm 38.69 \%$, mean \pm $\mathrm{SD})$. At the Front, females were in attendance most of the time $(85.1 \pm 28.69 \%)$.

Table 4. Pagophilus groenlandicus. Results of the classification trees (CARTs) exploring individual and sex differences within harp seal pup vocalizations recorded in the Atlantic Greenland Sea and the Front

\begin{tabular}{|c|c|c|c|c|c|c|c|c|c|c|}
\hline & $\begin{array}{l}\text { No. of } \\
\text { ind. }\end{array}$ & $\begin{array}{c}\text { No. of } \\
\text { calls }\end{array}$ & $\begin{array}{l}\text { First major } \\
\text { CART split }\end{array}$ & $\begin{array}{c}\text { Pups correctly } \\
\text { identified } \\
(\%)\end{array}$ & $\begin{array}{l}\text { No. of } \\
\text { female } \\
\text { pups }\end{array}$ & $\begin{array}{c}\text { Females } \\
\text { correctly } \\
\text { identified } \\
(\%)\end{array}$ & $\begin{array}{c}\text { Misclassified } \\
\text { female calls } \\
(\%)\end{array}$ & $\begin{array}{l}\text { No. of } \\
\text { male } \\
\text { pups }\end{array}$ & $\begin{array}{c}\text { Males } \\
\text { correctly } \\
\text { identified } \\
(\%)\end{array}$ & $\begin{array}{l}\text { Misclassified } \\
\text { male calls } \\
(\%)\end{array}$ \\
\hline $\begin{array}{l}\text { Greenland } \\
\text { Sea }\end{array}$ & 91 & 4075 & $\begin{array}{l}\text { 3rd peak } \\
\text { frequency } \\
(\mathrm{PF} 3)\end{array}$ & 43 & 42 & 55 & 14 & 47 & 8 & 86 \\
\hline Front & 25 & 984 & $\begin{array}{l}\text { 1st peak } \\
\text { frequency } \\
\text { (PF1) }\end{array}$ & 32 & 13 & 38 & 66 & 12 & 42 & 34 \\
\hline
\end{tabular}



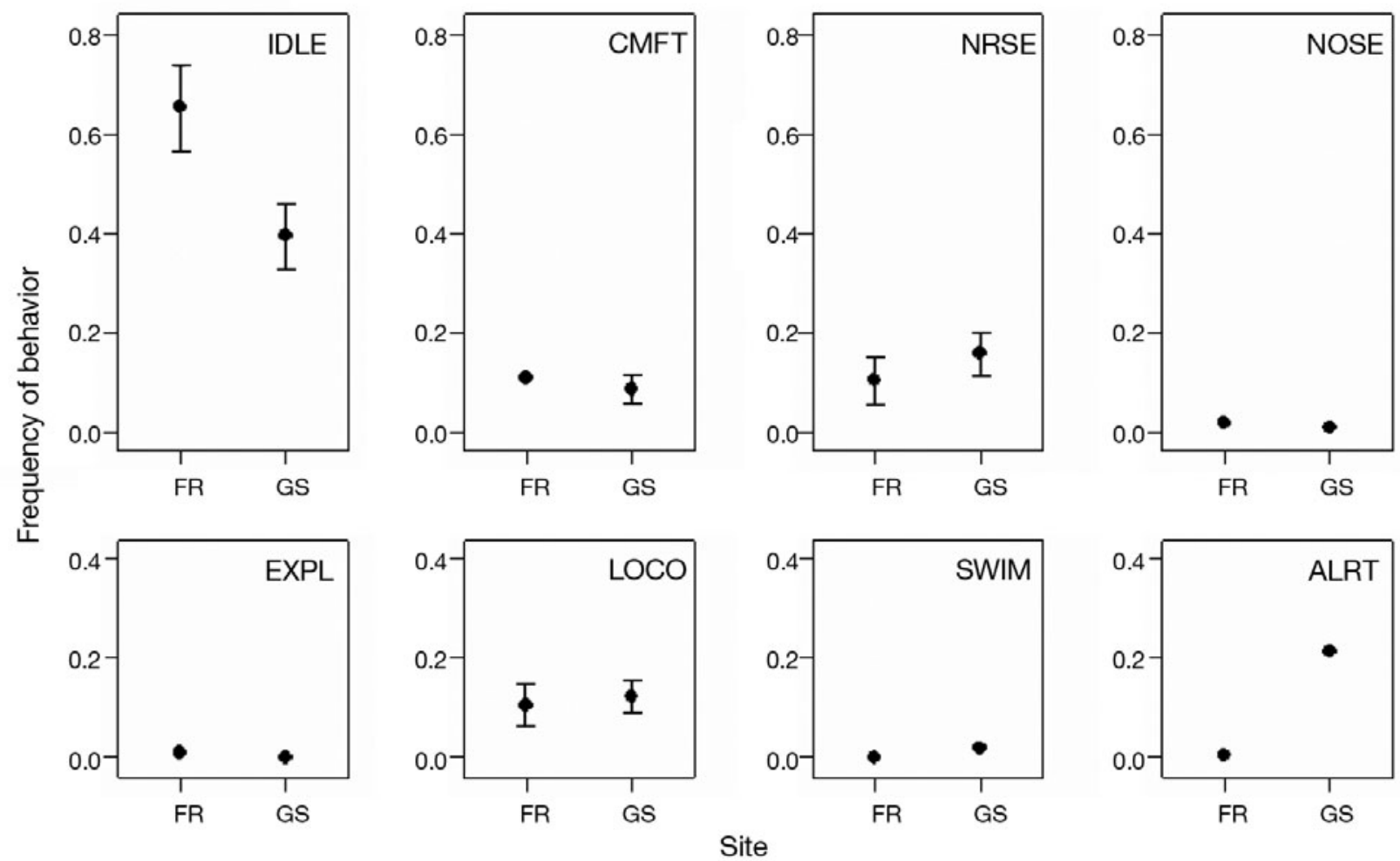

Fig. 4. Pagophilus groenlandicus. Mean \pm SD for the 8 observed behaviors: idle (IDLE), comfort movements (CMFT), nursing (NRSE), nosing (NOSE), exploration (EXPL), locomotion (LOCO), swimming (SWIM) and alert (ALRT), for harp seal pups at the Front $(F R, n=58)$ and the Greenland Sea $(G S, n=78)$

Table 5. Pagophilus groenlandicus. Nonparametric MANOVA (Anderson 2001) testing for effects of site (Greenland Sea or Newfoundland) and harp seal pup stage $(1,2,3+$, see 'Material and methods' for details of staging) and site-stage interaction. Eight units of behavior - idle, comfort movements, nursing, nosing, locomotion, swimming, exploration, and alert-were included in the analysis. Note that the $F$-values are pseudo- $F$ values (see Anderson 2001 for details) rather than Fisher's F-ratio

\begin{tabular}{|lcrlllr|}
\hline & df & SS & MS & $F_{\text {Model }}$ & $\mathrm{R}^{2}$ & $\mathrm{p}$ \\
\hline Site & 1 & 2.952 & 2.952 & 27.044 & 0.167 & $<0.001$ \\
PupStage & 2 & 0.603 & 0.301 & 2.762 & 0.034 & 0.113 \\
Site $\times$ PupStage & 2 & 0.040 & 0.020 & 0.185 & 0.002 & 0.993 \\
Residuals & 130 & 14.191 & 0.109 & 0.798 & & \\
Total & 135 & 17.786 & & & 1.000 & \\
\hline
\end{tabular}

Table 6. Pagophilus groenlandicus. Quasi-binomial generalized linear model testing the effect of site (Greenland Sea, Front) on pup attendance by female harp seals. ${ }^{* *}$ Significant at $\mathrm{p}<0.05$

\begin{tabular}{|lrrrc|}
\hline & Estimate & SE & $t$ & $\mathrm{p}$ \\
\hline Intercept & 1.7771 & 0.2936 & 6.052 & $1.35 \times 10^{-8 * *}$ \\
Site (Greenland & -1.5225 & 0.3454 & -4.408 & $2.12 \times 10^{-5 * *}$ \\
Sea compared to Front) & & & \\
\hline
\end{tabular}

\section{DISCUSSION}

\section{Pup vocal behavior}

We investigated the vocal behavior of harp seal pups in the Front by exploring a range of acoustic parameters, most of which have been shown to be important for recognition between mothers and pups in other pinnipeds (Insley 1992, Charrier et al. 2002, Insley et al. 2003). There was low variation ( 40\%) among pups at the Front, perhaps owing to confounding factors, such as age and sex. Nonetheless, we think that this low variation suggests that vocal recognition may not be the sole means of recognition between mother and pup harp seal pairs in the Front. Other studies of the Canadian harp seal population in the Gulf of St. Lawrence reached similar conclusions and suggested that olfaction and the use of spatial memory were likely important cues for the relocation and recognition of pups by females (Terhune et al. 1979, Kovacs 1987, 1995).

Our analyses of vocal behavior of harp seal pups from the Greenland Sea showed a significantly higher 
proportion of correctly classified vocalizations for female pups than for male pups, suggesting that vocalizations of female pups are considerably more distinct than those of male pups (Van Opzeeland \& Van Parijs 2004). Similar analyses of harp seal pup vocal behavior in the Front, however, showed no significant differences between the proportion of correctly classified vocalizations for female and male pups. For the Greenland Sea it was suggested that female harp seal pup individuality may serve a function during later developmental age classes (Van Opzeeland \& Van Parijs 2004). Adult female harp seals are evidently faithful to particular locations (Sergeant 1991, Perry et al. 2000), which may lead to selection for distinctive vocalizations among related females. However, unless females exhibit population level differences in their behavior patterns, this hypothesis would not explain the similar proportions of correctly classified vocalizations observed between males and female pups at the Front.

The duration of vocalizations of pups was the acoustic parameter that separated calls of pups according to location. Pup calls recorded in the Greenland Sea were longer than calls recorded in the Front. Several studies have suggested that lengthening of calls may be a response to reduce overlap with conspecific calls, which may occur in dense aggregations of animals (Watkins \& Schevill 1968, Terhune et al. 1994). However, the sizes of the Greenland Sea breeding patches were smaller compared to the Front breeding patches (4700 and 82600 pups in the Greenland Sea vs. 368705 and 272074 pups in the Front). Although we do not have detailed breeding patch density estimations, we do not think that a difference in density of the 2 harp seal breeding aggregations can explain the observed differences in durations of calls of pups.

Perry \& Terhune (1999) reported variation in underwater vocalizations of adult harp seals among different breeding locations. Vocalizations obtained from the Gulf and Front components did not differ from each other, but did differ from the underwater vocalizations from the Greenland Sea herd (Perry \& Terhune 1999). Similarly, we found evidence for geographic variation in vocal behavior of harp seal pups, perhaps owing to several factors though the reasons for these differences are not clear.

\section{Mother-pup behavior}

Female attendance differed significantly between the 2 sites; the age of the pup was not a significant factor to explain these differences. In the Greenland Sea, mothers attended pups for fewer hours in the afternoon and evening, and nursed their pups for longer periods, compared to mothers in the Front. There are several possible explanations for what may be driving the behavioral and acoustic differences between these populations, some of which may act in combination.

Females may have adjusted their behavior in response to hunting by humans to maximize their time in the water. We do not think that the risk of predation by polar bears can explain these differences, as very few bears evidently travel out as far as the northern Greenland ice, compared with significant polar bear presence at the Front (Wiig et al. 2003). However, harp seals have been harvested commercially since the 1700s, with the Canadian hunt starting earlier than the Greenland Sea hunt (Haug et al. 2006, Skaug et al 2007). Although the current hunt in the Greenland Sea is almost 2 orders of magnitude smaller than the Canadian hunt, the Greenland Sea population has been reduced to a smaller proportion of its initial population size than the Canadian population (Hammill \& Stenson 2007, Skaug et al. 2007) and current pup production in the Greenland Sea is approximately an order of magnitude smaller than that in Canadian waters (Haug et al. 2006). Harvesting might have evolutionary consequences depending on the intensity of the hunt and the age classes targeted (Coltman 2008, Wirsing et al. 2008).

Geographic location and density might also affect maternal behavior as there was a large difference in the sizes of the Greenland Sea and Front breeding patches. Previous studies report varying effects of population density on maternal behavior (e.g. Boness et al. 1998, Bradshaw et al. 2000). However, more data, including detailed density estimations, behavioral observations on mothers and estimates of pup condition, are necessary to investigate the potential effect of whelping patch density on harp seal mother-pup behavior.

Some phocids might adjust their diving behavior and the timing of foraging in response to prey availability and movements (Kooyman 1975, Burns et al. 2008). Female harp seals leave their pups during the lactation period to forage under the ice. Therefore, site-specific differences in temporal patterns of prey behavior may also influence female attendance patterns.

Environmental conditions such as ice thickness, weather (i.e. wind speed, air temperature), or both, fluctuate substantially among sites and years. Weather conditions have been suggested to influence haul out patterns of females with pups in several ice-breeding seal species (Finley 1979, Thomas \& DeMaster 1983). The observed differences in mother-pup behavior could therefore be related to geographic differences in environmental conditions.

Recent climatic variations have resulted in changes in the dynamics of ice and thaw, increasing the unpredictability of ice cover in all Arctic areas (Tynan \& DeMaster 1997, Serreze et al. 2003). Serreze et al. 
(2003) reported a record minimum Arctic sea ice extent in 2002, the year during which the behavioral and acoustic data were collected in the Greenland Sea. In addition, several studies suggest that the largest decreases in sea ice extent as a result of climate change occur in areas with multi-year ice (e.g. Serreze et al. 2003, Nghiem et al. 2007). To examine whether the ice extent and composition in 2002 in the Greenland Sea differed from other years, we used data from the Center for Satellite Exploitation and Research (CERSAT, http://cersat.ifremer.fr) database to plot the backscatter coefficients and sea ice concentration for March for both study areas over a period of 6 yr. Sea ice concentration indicates the sea ice extent (areas with $<15 \%$ ice concentration represent open water). The backscatter coefficient provides information on the sea-ice age: low backscatter coefficients indicate pure firstyear ice, whereas high backscatter coefficients indicate pure multi-year ice that has survived the melt period and is less saline than first-year ice. Intermediate coefficient values represent mixed ice types. When we compared backscatter and sea-ice concentration data from March 2000 to 2006 for both areas, the plots did not show a clear difference in ice type composition within areas over this 6 yr period; multi-year ice was consistently the predominant ice type in the Greenland Sea, whereas the Front was made up of first-year ice (Fig. 5). Sea ice concentration data also did not show clear differences between years within both areas. Nevertheless, when the ice extent within areas where whelping patches were located were compared between years, the ice extent in the Front area was low in 2004 compared to the other years, whereas it remained fairly constant over 2000 to 2006 in the Greenland Sea whelping patch area (Fig. 5). Friedlaender et al. (2007) reported the sea ice cover in the Front to have been below average ice cover in the period 1996 to 2006 and suggested that lack of solid ice may result in reduced reproductive success of adult harp and hooded seal females, increased pup mortality and changes in food availability. The observed differences in harp seal mother-pup behavior between the 2 sites could therefore be a result of the low sea ice extent in 2004 in the Front area, suggesting that the observed differences are a mere year-effect and potentially differ from years with average sea ice cover extent. However, as sea ice

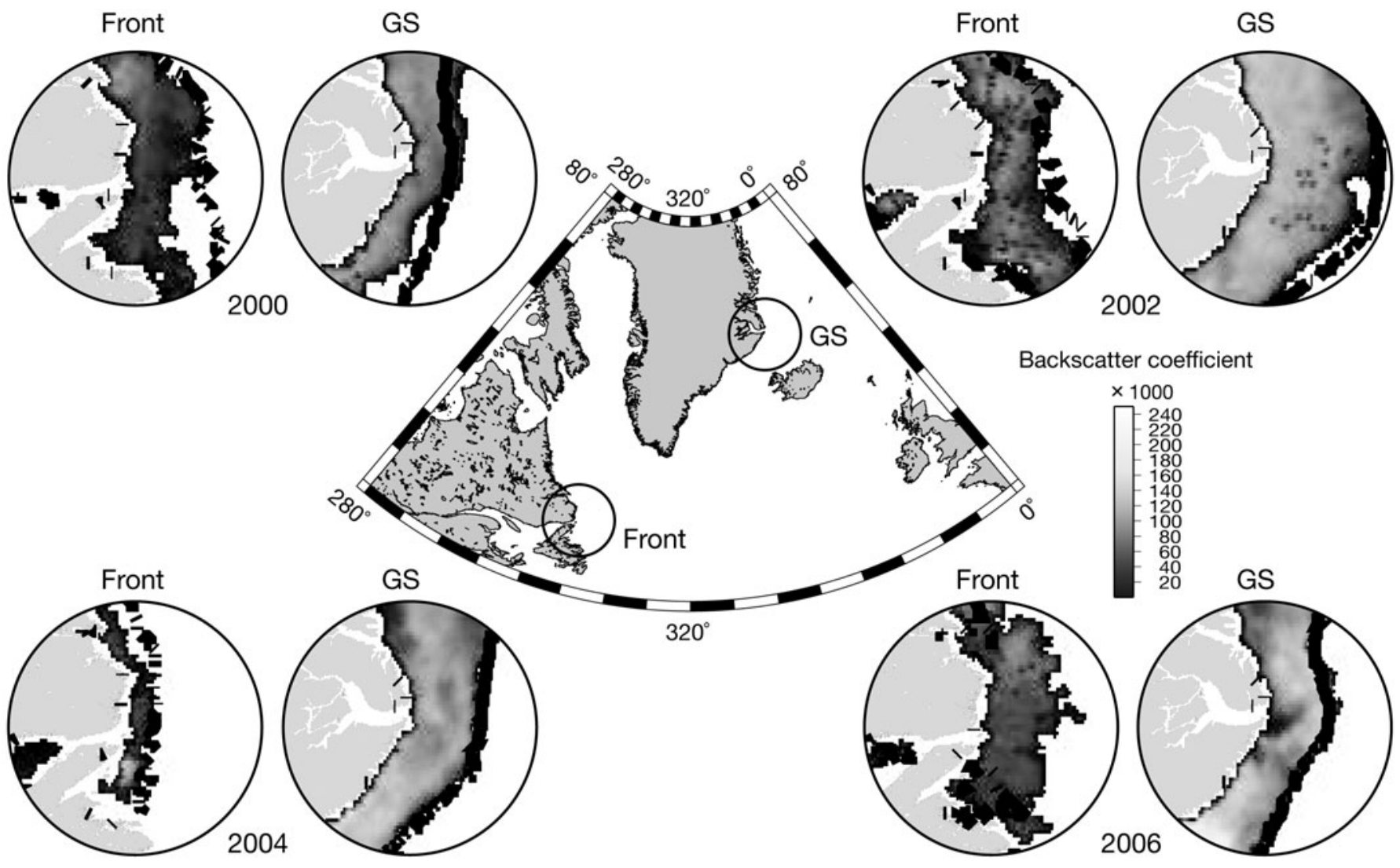

Fig. 5. Backscatter plot based on satellite imaging data from the CERSAT database showing March ice composition and extent for both study areas. High backscatter coefficients (white) indicate pure perennial (multi-year) ice, whereas low backscatter coefficients (black) indicate pure seasonal (first-year) ice. Black line (visible in some panels): boundary of $15 \%$ ice concentration; GS: Greenland Sea 
extent has been below average for several years in this area (Friedlaender et al. 2007), differences in harp seal mother-pup behavior in the Front area may also reflect the effects of persistent changes in ice extent. In bearded seals, it has been shown that fluctuations in ice cover can affect the number of displaying males and their display behavior (Van Parijs et al. 2004). It is plausible that changing ice conditions also influence female behavior.

A number of plausible hypotheses exist that may explain the behavioral and acoustic variability observed in female harp seals and their pups within this study. However, the one conclusion that can be drawn from this study is that there is still little understanding with regards to the behavioral ecology of these populations and the drivers behind the decision-making processes for this species. The results of this study indicate that in addition to the traditional methods of studying population dynamics and ecology, behavioral studies can provide further insights into differentiation of populations and the potential effects of changing environments on populations. Given drastic climatic changes facing the Arctic, the current lack of data is likely to impede us in understanding the effects of habitat loss on harp seal populations world wide.

Acknowledgements. We thank T. Haug for providing us the opportunity to carry out our field work in the Greenland Sea during the 2002 harp seal cruise. C. Duck, D. McKinnon, D. Wakeham, L. Lindblom, P. Abgrall, S. Tucker and I. Stenhouse helped with aspects of the field work. L. Rabenstein kindly helped with handling the CERSAT ice data. We did not need permits or licenses to collect behavioral or acoustic data in the Greenland Sea. For data collection in the Front, a scientific permit issued under the Marine Mammal Regulations (MMR, part of the Fisheries Act) was obtained and the project was approved by the DFO animal care committee. Funding was provided by the Amundsen Center for Arctic Research and the Faculty of Science of the University of Groningen.

\section{LITERATURE CITED}

Anderson MJ (2001) A new method for non-parametric multivariate analysis of variance. Austral Ecol 26:32-46

Boness DJ, Craig MP, Honigman L, Austin S (1998) Fostering behavior and the effect of female density in Hawaiian monk seals, Monachus schauinslandi. J Mammal 79: 1060-1069

Bradshaw CJA, Davis LS, Lalas C, Harcourt RG (2000) Geographic and temporal variation in the condition of pups of the New Zealand fur seal (Arctocephalus forsteri): evidence for density dependence and differences in the marine environment. J Zool 252:41-51

Burns JM, Hindell MA, Bradshaw CJA, Costa DP (2008) Finescale habitat selection of crabeater seals as determined by diving behavior. Deep Sea Res II 55:500-514

> Charrier I, Mathevon N, Jouventin P (2002) How does a fur seal mother recognize the voice of her pup? An experimental study of Arctocephalus tropicalis. J Exp Biol 205: $603-612$
Coltman DW (2008) Molecular ecological approaches to studying the evolutionary impact of selective harvesting in wildlife. Mol Ecol 17:221-235

De'ath G, Fabricius KE (2000) Classification and regression trees: a powerful yet simple technique for ecological data analysis. Ecology 81:3178-3192

> Excoffier L, Smouse PE, Quattro JM (1992) Analysis of molecular variance inferred from metric distances among DNA haplotypes: application to human mitochondrial DNA restriction data. Genetics 131:479-491

> Finley KJ (1979) Haul-out behaviour and densities of ringed seals (Phoca hispida) in the Barrow Strait area, N.W.T. Can J Zool 57:1985-1997

- Foster SA (1999) The geography of behaviour: an evolutionary perspective. Trends Ecol Evol 14:190-195

Friedlaender AS, Johnston DW, Fink SL, Lavigne DM (2007) Variation in ice cover on the East Coast of Canada, February-March, 1969-2006: implications for harp and hooded seals. Intl Fund Animal Welfare Tech Rep 2007-1

> Hammill MO, Stenson GB (2007) Application of the precautionary approach and conservation reference points to management of Atlantic seals. ICES J Mar Sci 64:702-706

> Haug T, Stenson GB, Corkeron PJ, Nilssen KT (2006) Estimation of harp seal (Pagophilus groenlandicus) pup production in the North Atlantic completed: results from surveys in the Greenland Sea in 2002. ICES J Mar Sci 63:95-104

> Insley SJ (1992) Mother-offspring separation and acoustic stereotypy: a comparison of call morphology in two species of pinnipeds. Behaviour 120:103-122

> Insley SJ, Phillips AV, Charrier I (2003) A review of social recognition in pinnipeds. Aquat Mamm 29:181-201

- Kooyman GL (1975) A comparison between day and night diving in the Weddell seal. J Mammal 56:563-574

Kovacs KM (1987) Maternal behaviour and early behavioural ontogeny of harp seals, Phoca groenlandica. Anim Behav 35:844-855

Kovacs KM (1995) Mother-pup reunions in harp seals, Phoca groenlandica: cues for the relocation of pups. Can J Zool 73:843-849

Lydersen C, Kovacs KM (1993) Diving behaviour of lactating harp seal, Phoca groenlandica, females from the Gulf of St Lawrence, Canada. Anim Behav 46:1213-1221

Lydersen C, Kovacs KM (1999) Behaviour and energetics of ice-breeding, North Atlantic phocid seals during the lactation period. Mar Ecol Prog Ser 187:265-281

McCulloch S, Boness DJ (2000) Mother-pup vocal recognition in the grey seal (Halichoerus grypus) of Sable Island, Nova Scotia. Can J Zool 251:449-455

McCulloch S, Pomeroy P, Slater PJB (1999) Individually distinctive pup vocalizations fail to prevent allo-suckling in grey seals. Can J Zool 77:716-723

Meisfjord J, Sundt RC (1996) Genetic variation between populations of the harp seal, Phoca groenlandica. ICES J Mar Sci 53:89-95

Miller EH, Murray AV (1995) Structure, complexity and organization of vocalizations in harp seal (Phoca groenlandica) pups. In: Kastelein RA, Thomas JA, Nachtigall PE (eds) Sensory systems of aquatic mammals. De Spil, Woerden, p 237-264

Nghiem SV, Rigor IG, Perovich DK, Clemente-Colon P, Weatherly JW, Neumann G (2007) Rapid reduction of Arctic perennial sea ice. Geophys Res Lett 34:L19504, doi:10. 1029/2007GL031138

Oksanen J, Kindt R, Legendre P, O'Hara B, Henry M, Stevens $\mathrm{H}$ (2007) The vegan package, R package 1.8-8. http://cran. r-project.org

Perry EA, Terhune JM (1999) Variation of harp seal (Pago- 
philus groenlandica) underwater vocalizations among three breeding locations. J Zool 249:181-186

Perry EA, Stenson GB, Bartlett SE, Davidson WS, Carr SM (2000) DNA sequence analysis identifies genetically distinguishable populations of harp seals (Pagophilus groenlandicus) in the NW and NE Atlantic. Mar Biol 137:53-58

Risch D, Clark CW, Corkeron PJ, Elepfandt A and others (2007) Vocalizations of male bearded seals, Erignathus barbatus: classification and geographical variation. Anim Behav 73:747-762

Sergeant DE (1991) Harp seals, man and ice. Canadian Special Publication of Fisheries and Aquatic Sciences 114:1-153

Serreze MC, Maslanik JA, Scambos TA, Fetterer F and others (2003) A record minimum arctic sea ice extent and area in 2002. Geophys Res Lett 30:1110, doi:10.1029/2002GL016406

Skaug HJ, Frimannslund L, Øien NI (2007) Historical population assessment of Barents Sea harp seals (Pagophilus groenlandicus). ICES J Mar Sci 64:1356-1365

Snack-Schiel SB (2003) The macrobiology of sea ice. In: Thomas DN, Dieckmann GS (eds) Sea ice: an introduction to its physics, chemistry, biology and geology. Blackwell, Oxford, p 240-267

Stenson GB, Hammill MO, Lawson J, Gosselin JF, Haug T (2005) Pup production of harp seals (Pagophilus groenlandicus), in the NW Atlantic. Canadian Science Advisory Secretariat. Res Doc 2005/037. Available at: http://www. dfo-mpo.gc.ca/csas/

Terhune JM (1994) Geographical variation of harp seal underwater vocalizations. Can J Zool 72:892-897

Terhune JM, Terhune ME, Ronald K (1979) Location and recognition of pups by adult female harp seals. Appl Anim Ethol 5:375-380

Terhune JM, Grandmaitre NC, Burton HR, Green K (1994) Weddell seals lengthen many underwater calls in response to conspecific vocalizations. Bioacoustics 5:223-226

Testa JW, Rothery P (1992) Effectiveness of various cattle ear tags as markers for Weddell seals. Mar Mamm Sci 8: $344-353$

Testa JW, Hill SEB, Siniff DB (1989) Diving behavior and maternal investment in Weddell seals (Leptonychotes weddellii). Mar Mamm Sci 5:399-405

Editorial responsibility: Brent Stewart, San Diego, California, USA
Therneau TM, Atkinson B (2004) rpart: recursive partioning. R Package Version 3.1-20. S-PLUS 6.x (available at http: //www.mayoresearch.mayo.edu/mayo/research/biostat/ splusfunctions.cfm)

> Thomas JA, DeMaster DP (1983) Diel haul-out patterns of Weddell seal (Leptonychotes weddelli) females and their pups. Can J Zool 61:1148-1456

Tynan CT, DeMaster DP (1997) Observations and predictions of Arctic climate change: potential effects on marine mammals. Arctic 50:308-322

Van Opzeeland IC, Van Parijs SM (2004) Individuality in harp seal, Phoca groenlandica, pup vocalizations. Anim Behav 68:1115-1123

Van Parijs SM, Hastie GD, Thompson PM (2000) Individual and geographic variation in the vocal behaviour of the harbour seal. Anim Behav 59:559-568

Van Parijs SM, Kovacs KM, Lydersen C (2001) Spatial and temporal distribution of vocalising male bearded seals implications for male mating strategies. Behaviour 138: 905-922

Van Parijs SM, Lydersen C, Kovacs KM (2003) Vocalizations and movements suggest alternative mating tactics in male bearded seals. Anim Behav 65:273-283

Van Parijs SM, Lydersen C, Kovacs KM (2004) Effects of ice cover on the behavioural patterns of aquatic-mating male bearded seals. Anim Behav 68:89-96

Venables WN, Ripley BD (2002) Modern applied statistics with S, 4th edn. Springer Verlag, New York

Watkins WA, Schevill WE (1968) Underwater playback of their own sounds to Leptonychotes (Weddell seals). J Mammal 49:287-296

> Wiig Ø, Born EW, Pedersen LT (2003) Movements of female polar bears (Ursus maritimus) in the East Greenland pack ice. Polar Biol 26:509-516

Wilkinson JP, Wadhams P (2005) A method of detecting change in ice conditions of the central Greenland Sea by the whelping patches of harp seals. J Clim 18:1216-1226

- Wirsing AJ, Heithaus MR, Frid A, Dill LM (2008) Seascapes of fear: evaluating sublethal predator effects experienced and generated by marine mammals. Mar Mamm Sci 24: $1-15$

Submitted: August 27, 2008; Accepted: June 9, 2009

Proofs received from author(s): July 13, 2009 